\title{
A novel method to correct for wood MOE ultrasonics and NIRS measurements on increment cores in Liquidambar styraciflua $\mathrm{L}$
}

\author{
Herizo Rakotovololonalimanana • Gilles Chaix • \\ Loïc Brancheriau • Lolona Ramamonjisoa • \\ Tahiana Ramananantoandro • Marie France Thevenon
}

Received: 21 November 2014 / Accepted: 23 February 2015 /Published online: 12 March 2015

(C) INRA and Springer-Verlag France 2015

\begin{abstract}
- Key message Ultrasounds overestimate the MOE value. This paper analyses the causes of this difference and opens the perspective for a novel method allowing the calculation of the correct MOE from ultrasounds or NIRS measurements on cores.

- Context Standardized methods for determining wood modulus of elasticity (MOE) are destructive and require many replicates. Other methods such as NIRS and ultrasound have been developed to characterize wood properties and overcome these constraints.

- Aim The aim of this study was to compare the two MOE measurement methods (NIRS and ultrasound) applied to cores of wood taken from standing trees (Liquidambar styraciflua).
\end{abstract}

Handling Editor: Jean-Michel Leban

Contribution of the co-authors Herizo RAKOTOVOLOLONALI MANANA performed the measurements, analysis, and wrote the paper. Gilles CHAIX, Loïc BRANCHERIAU and Marie France THEVENON designed the experiments. Gilles CHAIX, Lolona RAMAMONJISOA, Tahiana RAMANANANTOANDRO, and Marie France THEVENON supervised the work and coordinated the research project.

H. Rakotovololonalimanana $\cdot$ T. Ramananantoandro Université d'Antananarivo, Ecole Supérieure des Sciences Agronomiques, Départements des Eaux et Forêts,

BP 175 Antananarivo 101, Madagascar

G. Chaix

CIRAD, UMR AGAP, ESALQ USP, Piracicaba, SP, Brazil

\section{Ramamonjisoa}

Silo National des Graines Forestières, BP 5091, 101

Antananarivo, Madagascar

L. Brancheriau $(\triangle) \cdot$ M. F. Thevenon

CIRAD, UR BioWooEB, 34398 Montpellier Cedex 5, France

e-mail: loic.brancheriau@cirad.fr
- Methods MOE, measured by an acoustic method in standard samples $(360 \times 20 \times 20 \mathrm{~mm})$, was used as a reference. Then MOE was predicted by an NIRS model and determined using ultrasound in standard samples $(360 \times 20 \times 20 \mathrm{~mm})$, small samples $(10 \times 20 \times 20 \mathrm{~mm})$, and cores (15 $\mathrm{mm}$ in diameter).

- Result MOE values determined by acoustic method on standard samples and by ultrasonic method on small samples were correlated $\left(R^{2}=0.72\right)$ and were not statistically different. The NIRS PLS regression yielded a model with $R_{\mathrm{cv}}^{2}=0.80$. The link between NIRS and ultrasound on cores was statistically significant $\left(R^{2}=0.68\right)$.

- Conclusion The ultrasonic technique determines an apparent modulus enables comparative data analysis. This apparent modulus can be used for quantitative analysis if a corrective model is used. A correction formula to ultrasonic MOE was proposed in the case of a prismatic geometry.

Keywords Liquidambar styraciflua $\cdot$ Near infrared spectrometry $\cdot$ Ultrasonic measurement $\cdot$ Modulus of elasticity $\cdot$ Cores of wood

\section{Introduction}

The determination of modulus of elasticity (MOE) by standardized methods is time-consuming and requires large quantities of plant material. These methods are generally destructive for the test sample or the tree given that sample extraction requires its felling. Standardized methods therefore cannot be used to monitor changes in MOE during a tree's growth even though such information is important for the future use of its wood. An alternative technique is to use small samples such as cores. Previous studies (Perrin and Ferrand 1984; Bucur 1981, 
1986; Nepveu 1988; Pelletier et al. 2008) have shown that it is possible to determine shrinkage, growth stress, and MOE using cores taken from standing trees. MOE can be determined in cores by ultrasonic or near infrared spectrometry (NIRS) assessment. The studies conducted by Schimleck et al (2003), Baillères et al (2002); Schimleck and Evans (2004), Hein et al (2010), Chaix et al (2010), Leblon et al (2013), and Tsuchikawa and Schwanninger (2013) showed that NIRS is useful for predicting certain physicomechanical properties of wood. Bucur (1981) conducted ultrasonic measurements on 5-mm-diameter cores. More recent wood science studies (Brancheriau 2013; Ozyhar et al. 2013; $\mathrm{Xu}$ and Wang 2014) have improved ultrasonic measurement of MOE but the results obtained were not compared with those of standardized tests or other non-destructive methods. In order to measure MOE on increment cores, the study described herein aimed to (i) compare MOE values determined by the ultrasonic method with values obtained by modal analysis of flexural vibrations, (ii) identify the optimal model for determining MOE by near infrared spectrometry, and (iii) compare MOE values obtained using the ultrasonic method with those determined by NIRS.

\section{Materials and methods}

\subsection{Study materials}

This study is focused on Liquidambar styraciflua, a hardwood species of American origin. This species may be of interest for local wood markets in Madagascar because of its technological characteristics and color (American Hardwood Export Council 2008). L. styraciflua accounts for $30 \%$ of hardwood stocks in southern USA (Carter and Hughes 1984). The wood of this species is highly popular on American and European wood markets, especially for the production of pallets, paneling, or furniture, because of its suitability for staining and finishing (American Hardwood Export Council 2008 and 2009). The success of this species is attributed not only to its wood, but also to its great plasticity. L. styraciflua has a high potential to adapt to different environmental conditions and can be managed by coppicing from the stump (Colonado 1992). In addition, this species is fast growing and has great ability to colonize wasteland (Sabistina 2010). Finally, its abundant seeds multiply easily in the nursery and can be stored in cool dry environments without any decrease in germination potential for about 3 years (Bonner 1970). Based on this potential, $L$. styraciflua is of great interest for Madagascar because it fulfills the requirements of the Malagasy wood market (fast-growing species, multi-purpose wood, high plasticity, and relatively resistant to the passage of fire) (Chaix and Ramamonjisoa 2001).
As part of an international provenance trial on L. styraciflua, the Oxford Commonwealth Forestry Institute shipped Liquidambar seeds to Madagascar from 13 provenances mainly within the natural area of the species distribution, i.e., southeastern USA, Mexico, and Central America. These 13 Liquidambar provenances of were introduced at Mandraka (Madagascar) in 1986. Fifty-four 23- to 24 yearold trees were subsequently felled for thinning purposes. They were derived from the nine best provenances in terms of height and diameter. Two sampling areas were selected (foot of slope and ridge) to maximize the variability of the characters under study. Prismatic bars $(N=201,360 \times 20 \times 20 \mathrm{~mm}$ in $\mathrm{L}, \mathrm{R}, \mathrm{T}$ planes) were then cut from quartersawn boards. In addition, 99 radial cores $(15 \mathrm{~mm}$ diameter and $378 \mathrm{~mm}$ mean length) were taken from the dominant trees ( 25 years old). All samples were stabilized at $20^{\circ} \mathrm{C}, 65 \% \mathrm{RH}$.

\subsection{Experimental procedure}

Figure 1 depicts the experimental procedure used. The repeatability measurement of the acoustic and ultrasonic methods was determined experimentally by taking 30 measurements on a single prismatic bar (size and mass measured at each repetition). Thereafter, the MOE of 21 prismatic bars was measured by the acoustic method (MOE A) then the ultrasonic method (MOE US360). These samples were not tested in static bending as dynamic, and static moduli were shown to be quasi-identical in the case of clear wood samples $(360 \times 20 \times 20 \mathrm{~mm})$ (Brancheriau and Baillères 2002). A small $10 \times 20 \times 20 \mathrm{~mm}$ (L, R, and T) sample was then cut from the middle of each bar and triplicate MOE measurements were obtained by the ultrasonic method (MOE US10). The mean of the triplicate measurements/results was used thereafter as the MOE value and to determine whether the acoustic and ultrasonic methods yielded different MOE results on prismatic bars with 18 and 0.5 length/height ratios. An NIRS regression model (MOE NIRS) was built based on the MOE A values for the remaining 180 prismatic bars. The cores were cut and sanded to obtain parallel surfaces perpendicular to the longitudinal axis. Ultrasonic and NIRS measurements (MOE US and MOE NIRS) were obtained on these surfaces and repeated each $20 \mathrm{~mm}$ along the cores (1801 measurements). The cores were then used to compare the MOE US and MOE NIRS values.

\subsection{Free flexural vibration tests}

The sample was placed on two elastic mountings (vibration deflection on the L-T plane). A steel ball (diameter $13 \mathrm{~mm}$; weight $9 \mathrm{~g}$ ) was used to create an impact on one end of the bar and a laser vibrometer was placed at the other end. The sound generated was filtered (analogic filtering with frequency cutoff at $10 \mathrm{kHz}$ ) and then digitalized with 12-bit resolution. The acquisition parameters were set to ensure a frequency 
Fig. 1 Experimental setup (grey areas indicate the surface measured with NIRS)

Prismatic bars $(\mathrm{N}=\mathbf{2 0 1})$

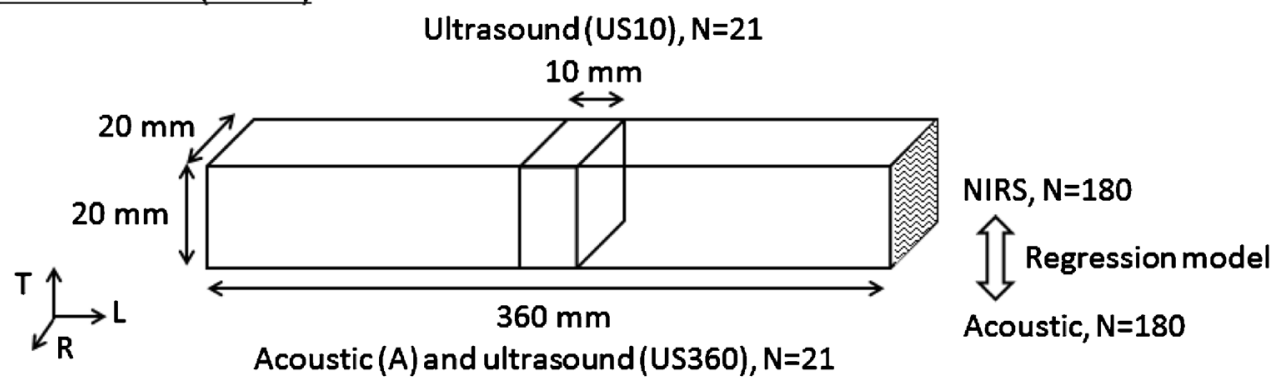

Radial cores $(\mathrm{N}=99)$

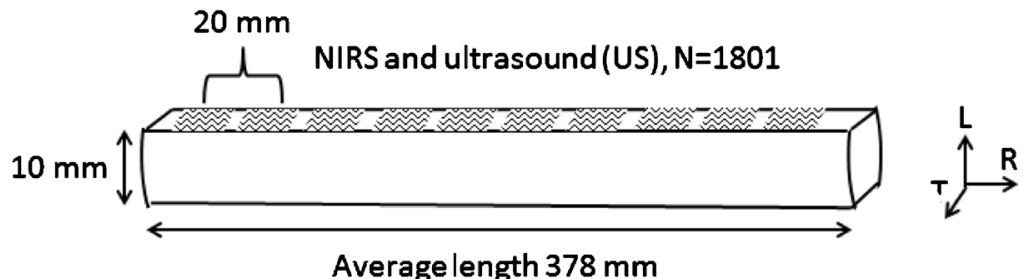

2.5 Near infrared spectrometry measurements

resolution of $\pm 1.35 \mathrm{~Hz}$ (first resonance frequency close to $790 \mathrm{~Hz}$ ). The first three frequencies were used to determine the MOE A based on Bordonné's solution to Timoshenko's theory (Brancheriau 2002).

\subsection{Ultrasound measurements}

The sample was placed between two ultrasound transducers with honey used as coupling material. Measurements were obtained in transmission mode at $1 \mathrm{MHz}$ emission frequency. The received signal was digitalized at 12-bit resolution. A computer algorithm calculated the propagation time by determining a threshold based on an analysis of the statistical properties of the signal noise. This determination method was appropriate in this case given that the signal-to-noise ratio was greater than $30 \mathrm{~dB}$. MOE US was determined by the conventional Eq. (1), where $\rho$ is the density, $\mathrm{L}$ is the sample length, and $\tau$ is the propagation time.

$\mathrm{MOE}=\rho\left(\frac{L}{\tau}\right)^{2}$

Emission and acquisition settings were specific to the length of the tested sample: square signal for five periods and time resolution of $\pm 0.2 \mu \mathrm{s}(0.3 \%$ error for the propagation time determined in a $360 \mathrm{~mm}$ sample); $\pm 0.05 \mu$ s pulse signal and time resolution $(2.5 \%$ error for the propagation time determined in a $10 \mathrm{~mm}$ sample). As the MOE US error was greater for small samples, the mean of triplicate measurements/results was used. Theoretically, 70 repetitions would be required to reduce the error to $0.3 \%$, but only three repetitions were performed given the high number of measurements.
Near infrared spectra were taken on the radial tangential plane of the prismatic bars. Chaix et al (2010) showed that regression models yield accurate predictions when measurements are made on this plane. A Bruker Vector 22/N spectrophotometer combined with OPUS version 5.0 software was used in diffuse reflectance mode with a sintered gold standard as reference. This Fourier transform spectrophotometer is designed for reflectance analysis of solids and contains an integrating sphere. The same instrument with the same control software was then used with the same settings to measure absorption spectra of the cores, again in the radial tangential plane. Spectra were acquired over a 12,500 to $3500 \mathrm{~cm}^{-1}$ (800 to $2850 \mathrm{~nm}$ ) range at $8 \mathrm{~cm}^{-1}$ resolution. Each spectrum was made up of 2335 absorption values, and 16 scans were averaged for each spectrum to improve the signal-to-noise ratio.

\subsection{Calibration of the near infrared spectrometry regression model}

Atypical spectra (outliers) were detected by principal components analysis (PCA) using Unscrambler version 9.7 software. PCA can be used to check the homogeneity of samples and detect atypical samples (Smith 2002; Bertrand 2005). The NIRS predicted values (MOE NIRS) were obtained by the model based on partial least squares (PLS) method using Unscrambler version 9.7 software. The PLS regression was used for a calibration that linked the reference data (MOE A values obtained with 180 prismatic bars of Liquidambar wood) to the information generated by the near infrared absorption spectra (Wold et al 2001; Giordanengo et al 2009). Before constructing the PLS regression, the spectra were converted to first- or second-order spectra using 
Savitzky and Golay's (1964) algorithm, then by standard normal variate (SNV) normalization. These data conversions improved the calibration quality by making effective use of and not degrading the spectral information (Naes et al; 2004; Hein et al 2010). The cross-validation technique with five random segments was used to test the preprocessing and build the NIRS calibration model for the MOE of Liquidambar wood. Then we divided the samples into two sets to test the best model, one for calibration (131 samples) and one for external validation (49 samples). The following criteria were used to select the appropriate calibration: (i) values of the coefficient of determination between measured values and values predicted by calibration $\left(R^{2} \mathrm{c}\right)$, or cross-validation $\left(R^{2} \mathrm{cv}\right)$, or by external validation $R^{2}$; (ii) root mean square error of calibration (RMSEC), root mean square error of cross-validation (RMSECV), root mean square error of prediction (RMSEP); and (iii) ratio of performance deviation (RPD), which was the ratio between the standard deviation $(\sigma)$ of the reference measurement of the samples considered and the RMSEP Eq. (2).

$\mathrm{RPD}=\frac{\sigma}{\mathrm{RMSEP}}$

The procedures used to calculate RMSEC, RMSECV, and RMSEP were developed and demonstrated by Burns and Ciurczak (2008) Eqs. (3) to (5).

RMSEC $=\sqrt{\frac{\sum_{i=1}^{N}\left(\widehat{y}_{\mathrm{i}}-y_{\mathrm{i}}\right)^{2}}{N-A}}$

RMSECV $=\sqrt{\frac{\sum_{i=1}^{N}\left(\widehat{y}_{\mathrm{i}}-y_{\mathrm{i}}\right)^{2}}{N-1}}$

$\mathrm{RMSEP}=\sqrt{\frac{\sum_{i=1}^{M}\left(\widehat{y}_{\mathrm{i}}-y_{\mathrm{i}}\right)^{2}}{M}}$

where $\hat{y}_{\mathrm{i}}$ and $\hat{y}_{\mathrm{CVi}}$ are obtained by testing the calibration equation directly on data from the calibration and validation samples, respectively. $\mathrm{A}$ is the number of latent variables in the model, $\mathrm{N}$ is the number of samples, and $\mathrm{M}$ is the number of samples for the external validation. For a model to be reliable, RMSEC, RMSECV, and RMSEP must be close in value, and as low as possible, $R^{2} \mathrm{c}, R^{2} \mathrm{cv}, R^{2}$, and RPD must be as high as possible (Schimleck and Evans 2004; Fujimoto et al 2008).

\subsection{Data processing}

An analysis of variance (ANOVA) was performed to compare the mean values of MOE A, MOE US10, and MOE US360. The statistical model is given hereafter Eq. (6).

$Y_{\mathrm{ij}}=\mu+E_{\mathrm{i}}+\varepsilon_{\mathrm{ij}}$

where $i=1, \ldots, M$ is the modality number associated with the fixed effect of measurement method, $\mathrm{j}=1, \ldots, \mathrm{N}$ is the observation number, $\mathrm{Y}_{\mathrm{ij}}$ is the MOE measurement $j$ using the method $i, \mu$ is the general mean, $\mathrm{E}_{\mathrm{i}}$ is the effect of the measurement method numbered $i, \varepsilon_{\mathrm{ij}}$ is the residual. Holm's method was then applied for each MOE value determined by the different methods to detect significant differences (Saporta 2006). A linear regression analysis was performed to identify the link between MOE US and MOE NIRS on cores. All the analyses were conducted using R software version i386 2.15.3 (R Development Core Team 2012).

\section{Results}

3.1 Comparison of acoustic and ultrasonic methods used on prismatic bars

Replicate measurements on the same $360 \mathrm{~mm}$ sample resulted in $2.4 \%$ error for MOE A (mean 17,630 Mpa; standard deviation $220 \mathrm{MPa}$ ) and $2.2 \%$ for MOE US360 (mean 18, $390 \mathrm{Mpa}$; standard deviation $200 \mathrm{MPa}$ ). The ultrasonic method using the $10 \mathrm{~mm}$ sample resulted in $11.5 \%$ error (MOE US10; mean 19,650 Mpa; standard deviation $1160 \mathrm{MPa})$. ANOVA (Table 1) revealed a significant difference $(p<0.01)$ between the mean values of MOE US360 and MOE A (difference of $1620 \mathrm{MPa}$, i.e., approximately $9 \%$ ). A difference (2150 MPa, i.e., $12 \%$ ) was also noted between MOE US10 and MOE US 360. The pairwise comparison of means showed that MOE US360 was greater than the two other MOE values (Table 1 and Fig. 2). The smallest difference was observed between MOE US10 and MOE A (530 MPa, i.e., 3 \%).

Table 1 Comparison of mean MOE values determined by acoustic and ultrasonic methods $(\mathrm{N}=21)$

\begin{tabular}{lllll}
\hline Method & Mean (MPa) & Contrast & Difference (MPa) & $p$ value \\
\hline US360 (a) & 18250 & A & 1620 & $<10^{-2}$ \\
US10 (b) & 16100 & US360 & 2150 & $<10^{-2}$ \\
A (b) & 16630 & US10 & 530 & 0.20 \\
\hline
\end{tabular}

US360, MOE measured by the ultrasonic method on $360 \mathrm{~mm}$ prismatic bars. US10, MOE measured by the ultrasonic method on $10 \mathrm{~mm}$ prismatic bars. A, MOE measured by the acoustic method on $360 \mathrm{~mm}$ prismatic bars. a and b, Classification by group, according to Holm's method 
Fig. 2 Boxplot and scatter plots of MOE values for the two different measurement methods $(N=21)$. A, acoustic method on $360 \mathrm{~mm}$ prismatic bars. US10, ultrasonic method on $10 \mathrm{~mm}$ prismatic bars. US360, ultrasonic method on $360 \mathrm{~mm}$ prismatic bars. a Boxplot, b scatter plot AUS360, c scatter plot A-US10, and $\mathbf{d}$ scatter plot US360-US10
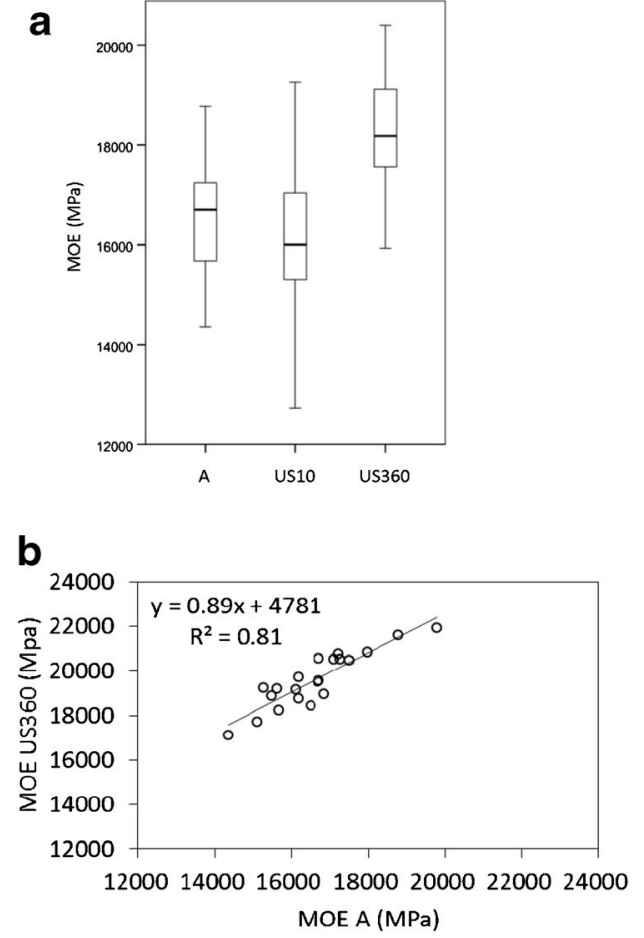
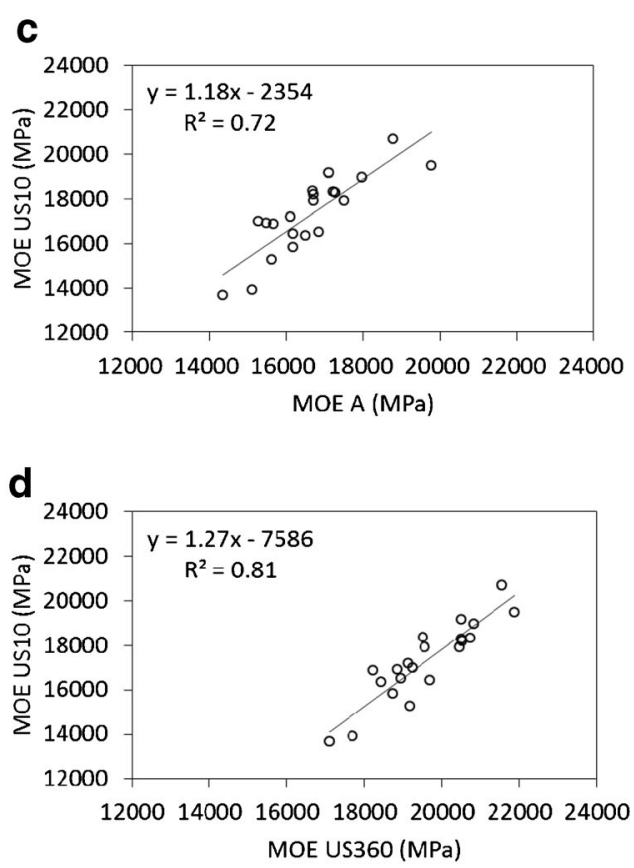

3.2 Comparison of the NIRS model and ultrasonic method used on cores

The NIRS regression model was built using MOE A values obtained on a subset of prismatic bars $(N=180)$ (Rakotovololonalimanana 2013). The best model in crossvalidation was obtained with spectra converted into firstorder spectra. The result of the regression yielded an $R^{2} \mathrm{c}$ of 0.82 and an $R^{2} \mathrm{cv}$ of 0.80 , with RMSEC at $1077 \mathrm{MPa}$ and RMSECV at $1165 \mathrm{MPa}$ (range 8668 to 23,220 Mpa with 14 outliers). The model prediction error determined by crossvalidation was $13 \%$. For the external validation, the $R^{2} \mathrm{cv}$ and the $R^{2}$ reached 0.81 and 0.82 , respectively, with RMSE $\mathrm{CV}$ at $1016 \mathrm{MPa}$ and RMSEP at $1234 \mathrm{MPa}$ (range 8668 to 23, $200 \mathrm{MPa}$ and 9006 to 20,290 MPa, with 12 and 2 outliers, respectively, Fig. 3). The performance deviation ratio (RPD= SD/RMSEP) was 2.3 , which is fully acceptable (Schimleck and Evans 2004).

The ultrasonic and NIRS methods (model in cross-validation, i.e., $N=180$, since the results were close due to the low group cross-validation number) were used to determine MOE values on core samples (1801 measurements, one measurement each $2 \mathrm{~cm}$ ). Descriptive statistics for the obtained MOE values are given in Table 2. The statistical distribution of the values was practically identical for the two methods, with a mean of 15,620 MPa for MOE US (standard deviation $2700 \mathrm{MPa}$ ) and 15,360 MPa for MOE NIRS (standard deviation $2420 \mathrm{MPa}$ ). Figure 4 shows the relation between MOE NIRS and MOE US. The linear relation was significant $(\mathrm{F}=$ $3003, p<0.001)$ with an $R^{2}$ value of $0.63(N=1801)$. The standard error of the estimate was $1508 \mathrm{MPa}$. This error was consistent with the standard errors obtained with MOE US10 and MOE A (950 MPa, Fig. 2c, Rakotovololonalimanana 2013) and the standard error obtained with the NIRS model (RMSEP of $1234 \mathrm{MPa}$ ). The linear regression shown in Fig. 4a nevertheless shows bias between the ultrasonic and NIRS models given that the regression coefficients were significantly different from zero $\left(\mathrm{MOE}_{\mathrm{NIRS}}=0.72 * \mathrm{MOE}_{\mathrm{US}}{ }^{+}\right.$ 3972). The pattern in Fig. $4 \mathrm{~b}$ shows that the points fall in a horizontal band with no apparent systematic features (randomly distributed residuals). The regression was not biased

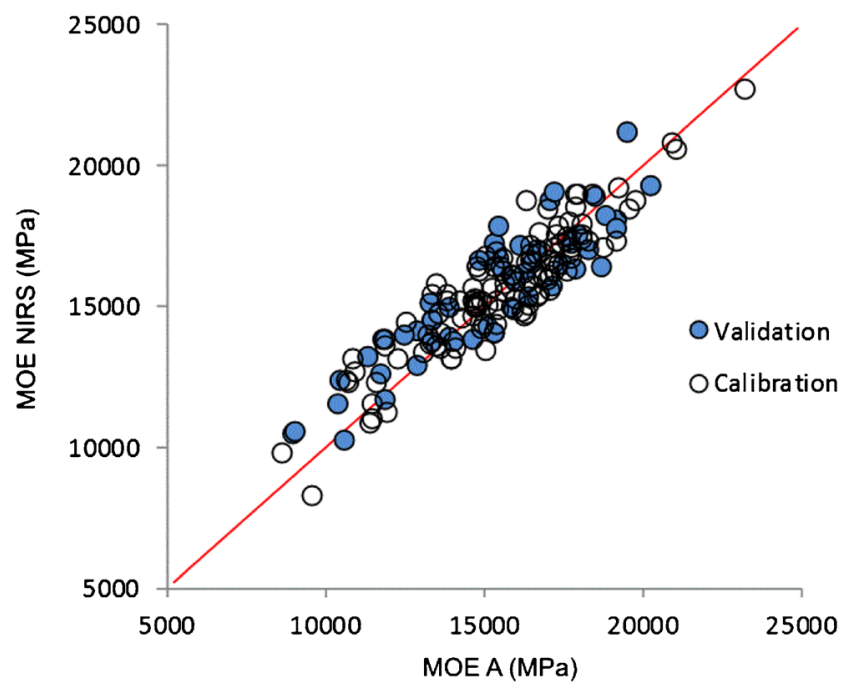

Fig. 3 NIR-predicted (MOE NIRS) versus measured values (MOE A) plotted for training (open circles) and external validation (filled circles) 
Table 2 Descriptive statistics for MOE values determined by ultrasonic (US) and NIRS methods on cores $(N=1801)$

\begin{tabular}{lll}
\hline Method & Mean (MPa) & SD (MPa) \\
\hline US & 15,620 & 2700 \\
NIRS & 15,360 & 2420 \\
\hline
\end{tabular}

by extreme values because no asymmetry was shown in Fig. 4b. The NIRS model was furthermore built using acoustic method values ranging from 8668 to $23,220 \mathrm{MPa}$ (22 points out of 1801 were outside the calibration interval in Fig. 4a).

\section{Discussion}

\subsection{Acoustic and ultrasonic methods}

The uncertainty of the acoustic method (2.4\%) was less than the theoretical value (4\%) proposed by Brancheriau and Baillères (2002) and Brancheriau (2002). In these studies, the first two vibration frequencies were used whereas three frequencies were taken into account in the present work. The difference in measurement uncertainty between the 360 and $10 \mathrm{~mm}$ prismatic bars measured by the ultrasonic method was due to differences in propagation time estimations and in sample mass. The theoretical uncertainty associated with the ultrasonic method is expressed in Eq. (7), where $m$ is mass, $h$ is height, $w$ is width, $L$ is length, and $\tau$ is ultrasonic propagation time.

$\frac{|\Delta M O E|}{M O E}=\frac{|\Delta m|}{m}+\frac{|\Delta h|}{h}+\frac{|\Delta w|}{w}+\frac{|\Delta L|}{L}+2 \frac{|\Delta \tau|}{\tau}$

Numerical error values were as follows: $\Delta \mathrm{m}= \pm 0.1 \mathrm{~g}(\mathrm{~m}=$ $95 \mathrm{~g}$ for $\mathrm{L}=360 \mathrm{~mm}$ and $\mathrm{m}=2.6 \mathrm{~g}$ for $\mathrm{L}=10 \mathrm{~mm}) ; \Delta \mathrm{h}=\Delta \mathrm{w}=$ $\pm 0.1 \mathrm{~mm}(\mathrm{~h}=\mathrm{W}=20 \mathrm{~mm}) ; \Delta \mathrm{L}= \pm 1 \mathrm{~mm}(\mathrm{~L}=360 \mathrm{~mm})$ and $\Delta \mathrm{L}= \pm 0.1 \mathrm{~mm}(\mathrm{~L}=10 \mathrm{~mm}) ; \Delta \tau= \pm 0.2 \mu \mathrm{s}(\tau=74.6 \mu \mathrm{s}$ for $\mathrm{L}=360 \mathrm{~mm})$; and $\Delta \tau= \pm 0.05 \mu \mathrm{s}(\tau=2.07 \mu \mathrm{s}$ for $\mathrm{L}=10 \mathrm{~mm})$. Theoretical uncertainty in this case was $1.9 \%$ for a $360 \mathrm{~mm}$ sample and $10.6 \%$ for a $10 \mathrm{~mm}$ sample. The measurement errors were acceptable and within the same order of magnitude as those associated with normalized 3- or 4-point static
Fig. 4 Relationship between MOE values determined by the ultrasonic method (MOE US) and predicted by the NIRS model (MOE NIRS) on cores $(N=1801)$. a Scatter plot with linear regression. b Residual plot
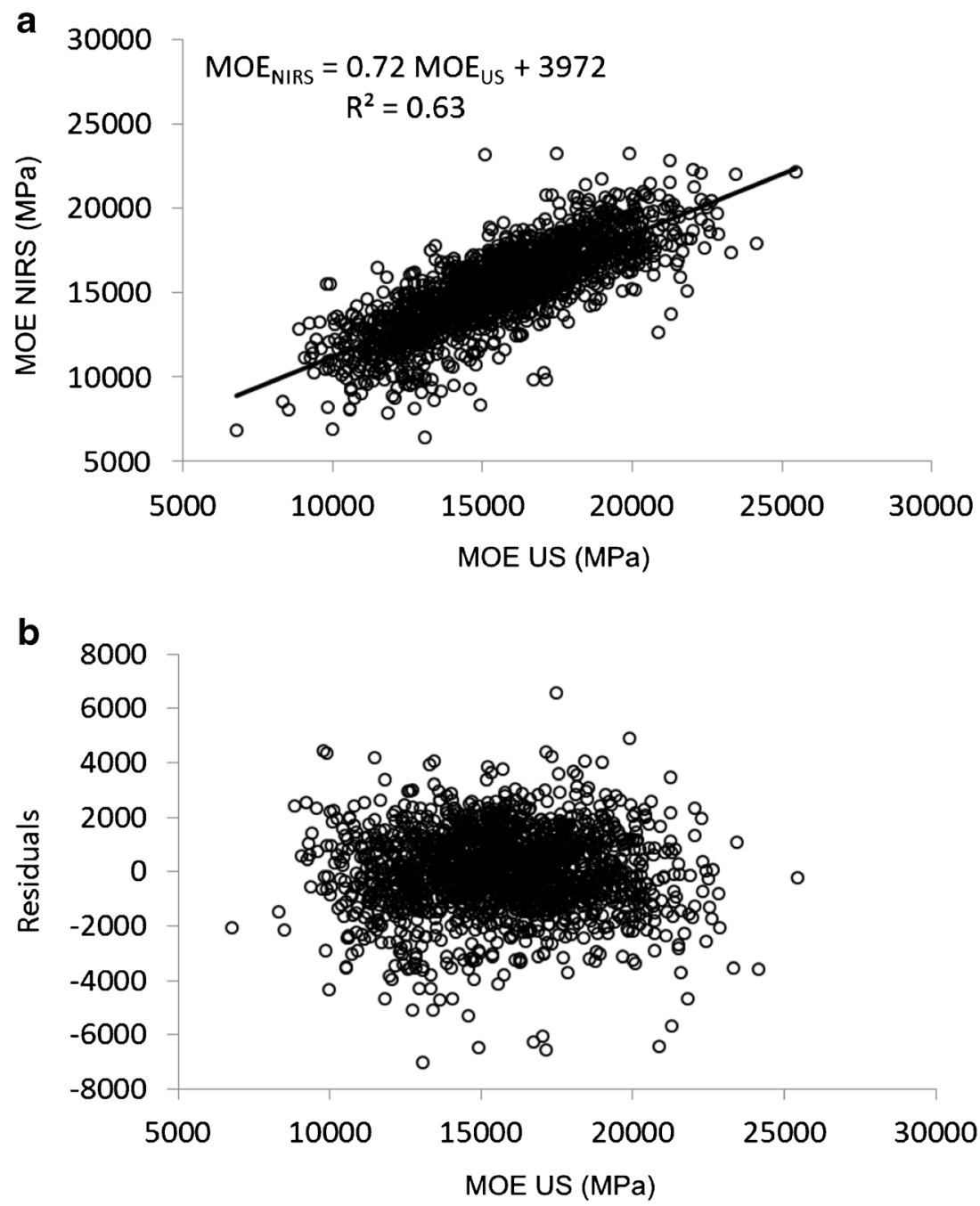
bending tests. Brancheriau et al (2002) reported a measurement error of $9 \%$ for the 3 -point bending test and $6 \%$ for the 4-point bend test on $360 \times 20 \times 20 \mathrm{~mm}$ samples.

The difference between MOE US360 and MOE US10 values was consistent with the results obtained by Bucur (1981) in beech (Table 3). The MOE values determined on prismatic bars with a length to height $(\mathrm{L} / \mathrm{h})$ ratio of 18 were higher than those obtained with bars with an $\mathrm{L} / \mathrm{h}$ ratio of 0.5 . The difference shown by Bucur (1981) was greater than seen here. This could be due to the difference in the geometry of the small samples (cores of $5 \mathrm{~mm}$ diameter and prismatic samples of $10 \mathrm{~mm}$ thickness). The effect of the sample length on MOE values could be explained by the influence of lateral movements (Poisson effect) (Rayleigh and Lindsay 1877; Love 1892). Lateral movements are not negligible when the $\mathrm{L} / \mathrm{h}$ ratio is "small" (Rayleigh and Lindsay 1877). Brancheriau (2002 and 2011) suggested an approximate solution (Eq. 8 is deduced from this solution) that takes this phenomenon into account, where $V_{\mathrm{X}}$ is the propagation speed along the $X$-axis, $M O E_{\mathrm{X}}$ is the MOE in the $X$-axis, $\rho$ is the density, $\mathrm{S}$ is the surface area of the right section, $\mathrm{L}$ is the length, $I_{\mathrm{Gz}}$ and $I_{\mathrm{Gy}}$ are inertias, and $v$ is the Poisson's coefficient.

$$
V_{\mathrm{X}}=\sqrt{\frac{M O E_{\mathrm{X}}}{\rho} \frac{1}{1+\frac{\pi^{2}}{S L^{2}}\left(I_{\mathrm{GZ}} v_{\mathrm{XY}}^{2}+I_{\mathrm{GY}} v_{\mathrm{XZ}}^{2}\right)}}
$$

In the present case, the directions (X, Y, and $\mathrm{Z}$ ) in Eq. (8) are collinear to the wood axes ( $\mathrm{L}, \mathrm{T}$, and $\mathrm{R}$ ). This equation was used to study the effect of the $(\mathrm{L} / \mathrm{h})$ ratio on the determined MOE values (Table 3). Values attributed to the Poisson coefficients were drawn from Guitard (1987) for so-called "standard" hardwood. The true MOE value is assumed to be that obtained by the acoustic method. In the simulation, the MOE of a $360 \mathrm{~mm}$ prismatic bar was compared with that of a $20 \mathrm{~mm}$ prismatic bar (not a $10 \mathrm{~mm}$ bar as in our study) as the model was used within its valid range. The theoretical difference in this case is $23 \%$, which is consistent with the experimental values. Note that for a $(\mathrm{L} / \mathrm{h})$ ratio above 7 , the apparent MOE calculated from the conventional Eq. (1) no longer varies and converges toward the true MOE value.

Table 3 Effect of sample length on MOE values determined by the ultrasonic method

\begin{tabular}{llr}
\hline Species & Relative difference $(\%)$ & \\
\hline Beech (Bucur 1981) & 32 & $\operatorname{MOE}(360 \times 20 \times 20 \mathrm{~mm})>$ \\
& & $\operatorname{MOE}$ core $(5 \mathrm{~mm})$ \\
Liquidambar & 12 & $\operatorname{MOE}(10 \times 20 \times 20 \mathrm{~mm})$ \\
& & $\operatorname{MOE}(360 \times 20 \times 20 \mathrm{~mm})>$ \\
Digital simulation & 23 & $\operatorname{MOE}(20 \times 20 \times 20 \mathrm{~mm})$ \\
& &
\end{tabular}

\subsection{NIRS model}

The NIRS model developed is comparable to models described in the literature for Eucalyptus species (which have technological properties similar to those of Liquidambar) and other species. Schimleck et al (2001) calibrated a model for Eucalyptus delegatensis and obtained an $R^{2}{ }_{\mathrm{cv}}$ of 0.90 (in cross-validation). Kothiyal and Raturi (2011) obtained an $R^{2}$ of 0.82 for Eucalyptus tereticornis (independent validation method with a performance to deviation ratio of 2.3). Most woods of the Eucalyptus genus have higher quantities of extractives than Liquidambar (Chein et al 2013; Rakotovololonalimanana 2013). Extractives have a major impact on the quality of NIRS models as the absorption spectra obtained are dependent upon the chemical composition of the wood and the covalent bonds therein (Schwanninger et al 2011). The fact that the quality of the model developed here was deemed to be only "fairly good" may be explained by the low levels of extractives in the test wood. Moreover, Narayanamurti et al (1962) reported that extractives have effects on the physico-mechanical properties of wood. The linear relation in Fig. 4 shows bias between the ultrasonic method and the NIRS predictive model. The NIRS model was calibrated with moduli determined by flexural vibration tests (MOE A). The ultrasonic test determined apparent moduli (Eq. 1) using the density and a propagation speed which depended on the frequency of the travelling wave (dispersion phenomenon, Brancheriau 2011). The apparent modulus was thus a function of the MOE, Poisson coefficients, and sample geometry (Eq. 8) but also of the material viscosity (the dispersion was due to the antagonist effects of viscosity and Poisson effect). The difference between moduli determined from vibration frequencies in bending and moduli determined from temporal vibrations in compression could explain the bias observed in Fig. 4. This bias could also be due to the age and quality of the trees from which the samples were taken since the samples intended for the acoustic measurements (reference measurements for the NIRS model) were taken from 23- to 24-year-old thinning trees whereas the cores were taken from dominant or co-dominant 25-year-old trees. Several previous studies (Maeglin 1987; Zobel and Buijtenen 1989; Jeffries 2008) confirmed that the tree age has an impact on the physico-mechanical properties of the wood.

\section{Conclusion}

The MOE values were determined by flexural vibrations (acoustic technique) and ultrasound on bars $(360 \times 20 \times$ $20 \mathrm{~mm})$ and small samples $(10 \times 20 \times 20 \mathrm{~mm})$. When these values were compared, a significant difference was noted between the acoustic and ultrasound findings on bars but there was no difference between acoustic values on bars and 
ultrasound values on small samples. The near infrared spectrometry model was obtained on bars based on the acoustic technique. This regression model was characterized by a prediction error of $1234 \mathrm{MPa}$. The associated performance to deviation ratio of 2.6 allowed us to use the model to predict MOE on cores. The ultrasound and NIRS techniques were compared on cores (linear regression on 1801 measurements). The standard error of the linear regression was in agreement with the determination error of the two techniques. A bias was however revealed by the regression, which highlighted a difference between ultrasound and NIRS (acoustic technique). The acoustic technique determined a MOE theoretically equivalent to that of a 4-point bending test (local modulus). The ultrasonic technique determined an apparent MOE mainly function of the MOE value, geometry, and Poisson coefficients for small samples. The use of ultrasound on cores is, however, possible because this leads to direct determination of the apparent MOE. Another advantage is that ultrasound could be used on small-diameter cores $(3 \mathrm{~mm})$. The present analysis proposed a correction formula to $\mathrm{MOE}$ obtained by ultrasounds in the case of a prismatic geometry. For complex geometries such as cores, the validity of the ultrasonic MOE correction should be verified using finite element analysis in order to allow for comparison with results from other studies that report on true static MOE.

Acknowledgments We thank S Lotte (CIRAD Ur BioWooEB) and instrument makers for machining wood samples, $\mathrm{P}$ Gallet and $\mathrm{S}$ Paradis (CIRAD Ur BioWooEB) for improving Us-Scan software, Honoré Randrianjafy and Hery Rakotondraoelina (DRFP/FOFIFA Madagascar) for providing material, LMGC (Laboratoire de Mécanique et Genie Civil) team, P Langbour, and D Guibal (CIRAD Ur BioWooEB) for providing technical support.

Funding Sample collection was funded by Centre de Coopération Internationale en Recherche Agronomique pour le Développement (CIRAD) in Montpellier, France and Département de Recherche Forestière et Piscicole (DRFP/FOFIFA) in Antananarivo, Madagascar. Laboratory work was funded by CIRAD. The main author received a grant from Agence Universitaire de la Francophonie during the 3 years of his $\mathrm{PhD}$ from 2011 to 2013. His $\mathrm{PhD}$ work was thereafter cofunded by CIRAD.

\section{References}

American Hardwood Export Council (2008) Sustainable American hardwood, a guide to species, p. 40

American Hardwood Export Council (2009) The illustrated guide to American hardwood lumber grades. National Hardwood Lumber Association, p. 24

Baillères H, Davrieux F, Ham-Pichavant F (2002) Near infrared analysis as a tool for rapid screening of some major wood characteristics in a eucalyptus breeding program. Ann For Sci 59:479-490

Bertrand D (2005) Etalonnage multidimensionnel : application aux données spectrales. Techniques de l'Ingénieur
Bonner FT (1970) Artificial ripening of sweetgum seeds. Tree Planters Notes 21:23-25

Brancheriau L (2002) Expertise mécanique des sciages par analyses des vibrations dans le domaine acoustique. Thèse de l'Université de la méditerranée - Aix Marseille II, Ecole Supérieure de Mécanique de Marseille. p. 267

Brancheriau L (2011) Corrections for poisson effect in longitudinal vibrations and shearing deformations in transverse vibrations applied to a prismatic orthotropic body in mechanical vibrations: types, testing and analysis, Amy L. Galloway (Ed.) Nova Science Publishers, ISBN-13: 978-1616682170, 205-223

Brancheriau L (2013) Caractérisation acoustique et ultrasonore des produits bois et composites. Habilitation à diriger des recherches, dossier de synthèse. Académie de Montpellier, Université de Montpellier 2, Information Structures et Systèmes, p.122

Brancheriau L, Baillères H (2002) Natural vibration analysis of clear wooden beams: a theoretical review. Wood Sci Technol 36:347-365

Brancheriau L, Baillères H, Guitard D (2002) Comparison between modulus of elasticity values calculated using 3 and 4 point bending tests on wooden samples. Wood Sci Technol 36:367-386

Bucur V (1981) Détermination du module d'Young du bois par une méthode dynamique sur carottes de sondage. Annales des Sciences Forestières 38:283-298

Bucur V (1986) Mesure sur carottes de sondage de quelques propriétés physiques de bois de hêtre à forte contraintes de croissance. Ann Sci For 43:115-124

Burns DA, Ciurczak EW (2008) Handbook of near infrared analysis, (3rd edition). CRC Press

Carter PM, Hughes CE (1984) Liquidambar styraciflua L.- a species of potential for the tropics. Commonw For Rev 63:207-216

Chaix G, Ramamonjisoa L (2001) Production de semences pour les reboisements malgaches. Bois et Forêts des Tropiques 268:49-64

Chaix G, Kokutse AD, Ratovomboahangy B, Guibal D, Randrianjafy H, Rakotondraoelina H, Brancheriau L, Rakotovololonalimanana H, Hein PRG, Ramananantoandro T (2010) Prediction of radial and tangential shrinkages by near infrared spectroscopy: an example for Tectona grandis from Togo and for Liquidambar styraciflua from Madagascar. Cerne 16:66-73

Chein S-C, Xiao J-h, Tseng Y-H, Kuo Y-H, Wang S-Y (2013) Composition and fungial activity of balsam from Liquidambar farmosana Hance. Holzforschung 67:645-351

Colonado M (1992) Liquidambar styraciflua, Fire Effects Information System. U S Department of Agriculture, Forest Service, p. 9

R Development Core Team 2012 R: A language and environment for statistical computing. R Foundation for Statistical Computing, Vienna, Austria. http://www.R-project.org/

Fujimoto T, Kurata Y, Matsumoto K, Tsuchikawa S (2008) Aplication of near infrared spectroscopy for estimating wood mechanical properties of small and full length lumber. J Near Infrared Spectrosc 16: 529-537

Giordanengo T, Charpentier J-P, Boizot N, Roussel S, Roger J-M, Chaix G, Robin C, Mourey N (2009) Procédé de mesure rapide et non destructif des polyphénols du bois de chêne de tonnellerie. Revue Française d'œnologie 234:10-15

Guitard D (1987) Mécanique du matériau bois et composites. Cépaduès, Toulouse, $238 \mathrm{p}$

Hein PRG, Clair B, Brancheriau L, Chaix G (2010) Predicting microfibril angle in Eucalyptus wood from different wood faces and surface qualities using near infrared spectra. J Near Infrared Spectrosc 18: 455-464

Jeffries TM (2008) Relationships of Growth Rate and Mechanical Properties in Sweetgum, Liquidambar styraciflua. Master. Faculty of the Virginia Polytechnic Institute and State University, Blacksburg, p 107 
Jouan-Rimbaud D, Bouveresse E, Massart DL, de Noord OE (1999) Detection of prediction outliers and inliers in multivariate calibration. Anal Chim Acta 388:283-301

Kothiyal V, Raturi A (2011) Estimating mechanical properties and specific gravity for five-year-old Eucalyptus tereticornis having broad moisture content range by NIR spectroscopy. Holzforschung 65

Leblon B, Adedipe O, Hans G, Haddadi A, Tsuchikawa S, Burger J, Stirling R, Pirouz Z, Groves K, Nader J, LaRocque A (2013) A review of near-infrared spectroscopy for monitoring moisture content and density of solid wood. For Chron 89:595-606

Love AEH (1892) A treatise on the mathematical theory of elasticity, (edition of 1994) Cambridge University Press

Maeglin RR (1987) Juvenile wood, tension wood, and growth stress effects on processing hardwoods. Applying the latest research to hardwood problems: Hardwood symposium of the Hardwood Research, Memphis, p. 9

Naes T, Isaksson T, Fearn T, Davies T (2004) A User-friendly guide to Multivariate calibration and classification. NIR Publications, UK, p. 344

Narayanamurti BD, George J, Pant HC, Singh J (1962) Extractives in Teak. Silvae Genetica 11:57-63

Nepveu G (1988) Détermination de la qualité du bois par prélèvement non destructif. Revue Forestière Française, $\mathrm{n}^{\circ} \mathrm{sp}:$ : 62-70

Ozyhar T, Hering S, Sanabria SJ, Niemz P (2013) Determining moisturedependent elastic characteristics of beech wood by means of ultrasonic waves. Wood Sci Technol 47:329-341

Pelletier MC, Henson M, Boyton S, Thomas D, Vanclay J (2008) Genetic variation in shrinkage properties of Eucalyptus pilularis assessed using increment cores and test blocks. N Z J For Sci 38:194-210

Perrin JR, Ferrand JC (1984) Automatisation des mesures sur carottes de sondage de la densité du bois, de son retrait et des contraintes de croissance. Ann Sci For 41:69-86

Rakotovololonalimanana H (2013) Déterminisme génétique et environnemental des propriétés du bois de Liquidambar styraciflua L. de la Mandraka : adaptation aux reboisements malgaches et apports à la production ligneuse. Thèse de Doctorat, Université de Montpellier 2, Information Structures et Systèmes, Université d'Antananarivo, Ecole Supérieur des Sciences Agronomiques, département des Eaux et Forêts. p. 203

Rayleigh JWS, Lindsay RB (1877) The theory of sound. (edition of 1945). Dover Publications, New York, pp 243-305

Sabistina B (2010) Gum : après les paysagistes, il séduit les industriels. Le bois Int 8:15-16

Saporta G (2006) Probabilité Analyse des données et statistique: France, $619 \mathrm{p}$

Savitzky A, Golay MJE (1964) Smoothing and differentiation of data by simplified least squares procedures. Anal Chem 36:1627-1639

Schimleck LR, Evans R (2004) Estimation of Pinus radiata D. Don tracheid morphological characteristics by near infrared spectroscopy. Holzforschung 58:66-73

Schimleck LR, Evans R, llic J (2001) Estimation of Eucalyptus delegatensis wood properties by near infrared spectroscopy. Can J Forest Res 31:1671-1675

Schimleck LL, Mora C, Daniels RF (2003) Estimation of the physical wood properties of green Pinus taeda radial samples by near infrared spectroscopy. Can J Forest Res 33:2297-2305

Schwanninger M, Rodrigues JC, Fackler K (2011) A review of band assignments in near infrared spectra of wood and wood components. J Near Infrared Spectrosc 19:287-308

Smith LI (2002) A tutorial on principal components analysis. Cornell University, USA 51: 52

Tsuchikawa S, Schwanninger S (2013) A review of recent near infrared research for wood and paper-Part 2. Appl Spectrosc Rev 48:560 587

Wold S, Sjöström M, Erksson L (2001) PLS-regression: a basic tool of chemometrics. Chemom Intell Lab Syst 58:109-130

$\mathrm{Xu} \mathrm{H}$, Wang L (2014) Analysis of cold temperature effect on stress wave velocity in green wood. Holzforschung 68:693-698

Zobel BJ \& Buijtenen JPv (1989) Wood variation: its causes and control. Springer-Verlag 